\title{
Evaluation of natural plant extracts as antioxidants in a bovine in vitro model of oxidative stress
}

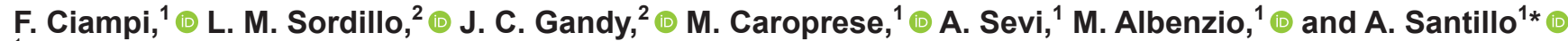 \\ ${ }^{1}$ Department of the Sciences of Agriculture, Food and Environment, University of Foggia, Via Napoli, 25, 71122 Foggia, Italy \\ ${ }^{2}$ Department of Large Animal Clinical Sciences, College of Veterinary Medicine, Michigan State University, East Lansing 48824
}

\begin{abstract}
Oxidative stress contributes to many inflammatorybased diseases of dairy cattle especially during periods of increased metabolic activity such as around calving. Endothelial cells play a key role in maintaining normal inflammatory responses, but they are especially susceptible to macromolecule damage during times of oxidative stress. Therefore, bovine aortic endothelial cells (BAEC) were used to study the effect of natural tanninbased extracts on oxidative stress that may improve health and well-being of cattle. Tannins are secondary metabolites in plants with potent antioxidant activity that have been used as natural feed additives for foodproducing animals. However, there is little information on how tannin-rich plant extracts may affect oxidative stress in dairy cattle. The objective of this study was to evaluate the antioxidant effect of pomegranate ( $P u$ nica granatum; PMG), tara (Caesalpinia spinosa; TA), chestnut (Castanea sativa; $\mathrm{CH}$ ), and gambier (Uncaria gambir; GM) natural extracts using an in vitro BAEC model of oxidative stress. Natural extracts were tested at a concentration of $80 \mu \mathrm{g} / \mathrm{mL}$. Viability, apoptosis, intracellular reactive oxygen species, and isoprostanes were determined on cultured BAEC treated with different plant natural extracts. No changes in cell viability was detected following PMG and GM treatments. In contrast, there was a $30 \%$ reduction of BAEC viability following treatment with $\mathrm{CH}$ or TA extracts. Intracellular reactive oxygen species production was significantly less abundant in cells treated with natural extracts than with the lipopolysaccharide control. Moreover, antioxidant activity varied according to the tested extract, showing a reduction of $63,45,51$, and $27 \%$ in PMG, GM, CH, and TA, respectively. The formation of isoprostanes as a consequence of lipid peroxidation after induction of oxidative stress also were significantly
\end{abstract}

Received January 9, 2020

Accepted May 10, 2020.

*Corresponding author: antonella.santillo@unifg.it decreased in PMG-treated cells when compared with the untreated cells. Theses findings suggest that PMG extract has the potential to mitigate oxidative stress without detrimental effects on cell viability. Further in vitro and in vivo research is warranted to explore the antioxidant potential of PMG extract as a dietary supplement to control oxidative stress in dairy cattle. Key words: bovine aortic endothelial cell, tannin-rich plant extract, oxidative stress, isoprostane, dairy cattle

\section{INTRODUCTION}

The periparturient period is a time when dairy cattle are susceptible to many metabolic and infectious diseases (Sordillo and Raphael, 2013). Oxidative stress was recognized for decades as contributing to compromised immune responses and increased health disorders around the time of calving (Sordillo and Aitken, 2009). Parturition and the onset of lactation results in increased metabolic activity, and excessive production of reactive oxygen species (ROS) occurs as by-products of enhanced cellular metabolism. The imbalance between ROS production and the availability of endogenous antioxidant defenses needed to neutralize ROS may expose dairy cattle to the damaging effects of oxidative stress (Castillo et al., 2013). For example, excessive ROS exposure can cause severe oxidative damage to biological molecules including nucleic acids, proteins, and lipids (Lykkesfeldt and Svendsen, 2007). Polyunsaturated fatty acids are especially susceptible to oxidative damage and results in lipid peroxidation of membrane phospholipids that can compromise normal cellular functions. Important biomarkers of lipid peroxidation damage are the isoprostanes (IsoP) that are derived from the oxidative of arachidonic acid by ROS. Indeed, IsoP were detected in the blood and milk of dairy cows during times of severe oxidative stress such as during the periparturient period and mastitis (Sordillo, 2018).

Previous studies used bovine endothelial cells as an in vitro model of how oxidative stress can contribute to dysfunctional inflammatory responses associated with 
the periparturient period and during diseases such as mastitis (Ryman et al., 2015). Endothelial cells regulate a wide range of inflammatory homeostatic mechanisms such as production of pro- and anti-inflammatory mediators and increase antioxidant pathways that help to coordinate leukocyte traffic and barrier function (Kadl and Leitinger, 2005). Many puplished reports have described the use of endothelial cell models to test the antioxidant effect of different molecules (Weiss et al., 2001; Song et al., 2009; Xu et al., 2010) including from the natural source (Motterlini et al., 2000). Therefore, BAEC were used in this study as an in vitro model to assess how tannin-rich plant extracts may mitigate dairy cattle responses to oxidative stress challenge.

Many of the endogenous antioxidant defense mechanisms that are used to balance ROS production in dairy cattle are derived from dietary sources such as vitamins and minerals (Sordillo, 2016). In the last decades of research, however, there has been a focus on exploring alternative natural compounds with antimicrobial, antiparasitic, and immunomodulation properties for food-producing animals (Yang et al., 2015). Among them, tannins from natural extracts probably are the most-studied compounds for farm ruminants to date (Huang et al., 2018). Tannins are common secondary metabolites in plants, and their function is related to microbial defense. Tannins may be classified in 2 main groups based on their structural characteristics as either hydrolyzable, such as gallotannins and gallic acid, or condensed, such as cathechins and quinic acid (Skowyra et al., 2014). Hydrolyzable tannins are one of the most potent antioxidants from plant sources that can neutralize free radicals and prevent celluar damage from occurring (Khan et al., 2000; Chambi, et al., 2013). Condensed tannins also were characterized for antioxidant properties (Desmarchelier et al., 1997), including catechin, which was identified as major bioactive compound (Anggraini et al., 2011).

To the best of our knowledge, no studies have been conducted that examine the effects of plant natural extracts on the oxidant status in bovine endothelial cells and their ability to mitigate oxidative stress biomarkers such as the IsoP. This information would be important as it may encourage the use of natural extracts as feed supplements for dairy cattle, especially during times of oxidative stress, such as the dry-off period or earlylactation period. The objective of this study was to evaluate the effect of pomegranate (Punica granatum; PMG), gambier (Uncaria gambir; GM), tara (Caesalpinia spinosa; TA), and chestnut (Castanea sativa; CH) natural extracts on ROS production and IsoP formation on cultured bovine endothelial cells in response to oxidant challenge.

\section{MATERIALS AND METHODS}

\section{Natural Extracts}

Pomegranate extract was kindly provided by Antonio Natalello (Department of Agriculture, Food and Environment, University of Catania, Catania, Italy) and was obtained using the residual part of PMG fruits containing peels, seeds, membranes, and portion of arils. The extracts of chestnut Nutri-P and tara T80 were obtained from Silvateam (San Michele Mondovì, Cuneo, Italy), and gambier RETAN-FGC was supplied by Figli di Guido Lapi S.P.A. (Castelfranco di Sotto, Pisa, Italy). All extracts were obtained by natural extraction process without use of chemical solvents. Tannin extract concentrations were determined as described by Natalello et al. (2020) and were $25 \mathrm{~g}$ of PMG/100 $\mathrm{g}$ of DM, $95 \mathrm{~g}$ of TA/100 $\mathrm{g}$ of DM, $75 \mathrm{~g}$ of $\mathrm{CH} / 100 \mathrm{~g}$ of DM, $48 \mathrm{~g}$ of GM/100 g of DM. Based on this purity, $0.1 \mathrm{~g}$ of each extract was put in a $50-\mathrm{mL}$ falcon tube and dissolved in $10 \mathrm{~mL}$ of Ham's F-12K (Sigma-Aldrich, Milan, Italy) culture medium to reach concentrations of $2.5 \mathrm{mg} / \mathrm{mL}$ PMG, $9.5 \mathrm{mg} / \mathrm{mL}$ TA, 7.5 $\mathrm{mg} / \mathrm{mL} \mathrm{CH}$, and $4.8 \mathrm{mg} / \mathrm{mL}$ GM. To obtain the same concentrantion in terms of tannin fraction, each extract was successively diluted at time of challenge to reach the concentration of $80 \mu \mathrm{g} / \mathrm{mL}$ for PMG, TA, CH, and GM. The tested concentration of natural extracts in the present study was chosen on the basis of previous results on viability of different cell lines in human and animal studies (Okonogi et al., 2007; Lee et al., 2011; Reggi et al., 2020).

\section{Bovine Aortic Endothelial Cell Isolation and Culturing}

Bovine aortic endothelial cells (BAEC) were collected from the aorta of healthy Holstein dairy cows based on techniques previously described by Sordillo et al. (1998). The BAEC were purified by dilution cloning techniques and then cultured in Ham's F-12K medium containing 10\% fetal bovine serum (FBS), $20 \mathrm{mM}$ HEPES, $2 \mathrm{~m} M$ L-glutamine, 1\% (vol/vol) antibioticantimycotic, heparin $(100 \mu \mathrm{g} / \mathrm{mL})$, insulin $(10 \mu \mathrm{g} / \mathrm{mL})$, transferrin $(5 \mu \mathrm{g} / \mathrm{mL})$, and sodium selenite (10 $\mathrm{ng} /$ $\mathrm{mL}$ ). Cells were revived from liquid nitrogen at passage 4 and used to passage 8 to 10 , and clones obtained from 4 different cows were used for each experiment. After thawing, the BAEC were cultured in a different flask until transferred to a T300 $\mathrm{cm}^{2}$ culture flask and detached with trypsin $0.05 \%$ at 80 to $90 \%$ of confluence to perform the assays. Trypan blue exclusion was used to evaluate cell death. Cells were collected using 
trypsin, diluted 1:10 in trypan blue, and counted on a hemocytometer to obtain the number of viable cells.

\section{Cell Viability}

Cells were plated at concentration of $4 \times 10^{4}$ cells/ $\mathrm{mL}$ in a 96-well plate and allowed to culture for $24 \mathrm{~h}$ before experimentation. Extract treatments were applied to BAEC cultures by replacing the base medium with culture media containing PMG, TA, CH, and GM treatments at $80 \mu \mathrm{g} / \mathrm{mL}$ with or without LPS exposure at $25 \mathrm{ng} / \mathrm{mL}$ and incubated for $12 \mathrm{~h}$ at $37^{\circ} \mathrm{C}$. The BAEC were exposed to LPS as positive control and to a culture medium without any treatments as negative control. The LPS concentration was determined on the basis of cell viability, which was more than $80 \%$ compared with negative control.

The viability of BAEC was measured using the Promega Cell Titer-Glo Viability Assay (Promega Corp., Madison, WI), which quantifies the amount of ATP, an indicator of metabolically active cells. A mixture of substrate and buffer results in cell lysis and generation of a luminescent signal proportional to the amount of ATP present. The amount of ATP directly reflects the number of viable cells. Luminescence was measured using a Wallac Victor3 1420 Multilabel Plate Reader (PerkinElmer Inc., Waltham, MA).

\section{Measurement of Cell Apoptosis and Death}

Apoptosis and death of BAEC exposed to treatments and LPS were measured using co-staining with YOPRO-1 and propidium iodide from a commercial kit (Thermo Fisher Scientific, Waltham, MA). Briefly, the cells were seeded the day before in $100-\mathrm{mm}$ petri dishes at concentration of $1 \times 10^{6}$ cells $/ \mathrm{mL}$, and treatments were applied as described in the previous paragraph. Apoptotic cells, which have altered membrane permeability, are permeable to a marker carbocyanine nucleic acid stain (YO-PRO-1), which exhibits green fluorescence. Dead cells were measured using propidium iodide, which exibits red fluorescence. Fluorescence was determined by flow cytometry (BD Biosciences Accuri C6, San Jose, CA) according to the manufacturer's protocols. Amounts of apoptotic and death cells were expressed as fold change over medium control.

\section{Intracellular ROS Production}

Cells were plated the day before assay at concentration of $4 \times 10^{4}$ cells $/ \mathrm{mL}$ in 96 -well plate. Treatments were applied as described above. The intracellular ROS production was measured with OxiSelect Intracellular ROS Assay Kit (Cell Biolabs, San Diego, CA). The flu- orescent probe chloromethyl-2,7-dichlorofluorescein diacetate diffuses through the cell membrane and is hydrolyzed by esterases to non-fluorescent dichlorofluorescein. In the presence of ROS, this compound is oxidized to highly fluorescent dichlorofluorescein. Briefly, BAEC were seeded in black 96-well plate overnight. The media were then changed to $0 \%$ FBS, $20 \mathrm{~m} M$ HEPES, 2 $\mathrm{m} M$ L-glutamine, $1 \%$ (vol/vol) antibiotic-antimycotic, heparin $(100 \mu \mathrm{g} / \mathrm{mL})$, insulin $(10 \mu \mathrm{g} / \mathrm{mL})$, transferrin $(5 \mu \mathrm{g} / \mathrm{mL})$, and sodium selenite $(10 \mathrm{ng} / \mathrm{mL})$ before the assay. Fluorescence was measured using a Wallac Victor3 1420 Multilabel Plate Reader (PerkinElmer Inc., Waltham, MA).

\section{Isoprostanes Analysis}

In the light of the results obtained for cell viability, apoptosis, death, and intracellular ROS production, PMG extract was chosen for further testing on isoprostanes analysis. The BAEC used for IsoP quantification were seeded the day before at concentration of $2 \times$ $10^{6}$ cells $/ \mathrm{mL}$ in 6 -well plate. At the time of challenge, the BAEC were pretreated with $80 \mu \mathrm{g} / \mathrm{mL}$ PMG and incubated for $6 \mathrm{~h}$ at $37^{\circ} \mathrm{C}$. Subsequently, treatments were applied by replacing the base medium with PMG at $80 \mu \mathrm{g} / \mathrm{mL}$ plus $5 \mathrm{mM} 2,2^{\prime}$-azobis (2-amidinopropane) dihydrochloride (AAPH), and culture media without any treatments were used as negative control; samples were incubated for $6 \mathrm{~h}$ at $37^{\circ} \mathrm{C}$ before IsoP quantification. The method described by Putman et al. (2018) for IsoP quantification in plasma samples was applied to cultured BAEC; supernatants were collected, extracted, and quantified using liquid chromatography-tandem MS. The specific isomers analyzed were $5,9 \alpha, 11 \alpha$-trihydroxy-( $8 \beta)$-prosta- $6 \mathrm{E}, 14 \mathrm{Z}$-dien-1-oic acid (5-iPF $\left.{ }_{2 \alpha}-\mathrm{VI}\right), \quad$ 12-iso-5(R),6E,14Z-prostaglandin $\mathrm{F}_{2 \alpha}\left(8,12\right.$-iso-iPF $\left.{ }_{2} \alpha \mathrm{VI}\right), 8$-iso-prostaglandin $\mathrm{E}_{2}$ (8-iso$\mathrm{PGE}_{2}$ ), 8-iso-15-keto-prostaglandin $\mathrm{E}_{2}$ (8-iso-15-keto$\left.\mathrm{PGE}_{2}\right)$, 8-iso-15(R)-prostaglandin $\mathrm{F}_{2 \alpha}$ [8-iso-15(R)$\left.\mathrm{PGF}_{2 \alpha}\right]$, 8-iso-prostaglandin A1 (8-iso-PGA $\left.\mathrm{PG}_{1}\right)$, 8-isoprostaglandin $\mathrm{A}_{2}$ (8-iso- $\mathrm{PGA}_{2}$ ), $15-\mathrm{F}_{2 \mathrm{t}}$-iso (formerly 8-iso-prostaglandin $\mathrm{F}_{2 \alpha}$ ), and 2,3-dinor-8-iso prostaglandin $\mathrm{F}_{2 \alpha}$ (2,3-dinor- 8-iso- $\left.\mathrm{PGF}_{2 \alpha}\right)$. Concentrations of IsoP were detected using electrospray ionization in negative-ion mode. Cone voltages and collision voltages were optimized for each analyte using Waters Quan Optimize (Waters Corporation, Milford, MA) software, and data analysis was carried out with Waters Target Lynx (Waters Corporation) software.

\section{Statistical Analysis}

Statistical analysis was conducted using SAS, University Edition (SAS Institute Inc., Cary, NC). Com- 
parisons of the means were made by one-way ANOVA followed by Tukey's post hoc correction test. The model used was Equation 1:

$$
\mathrm{y}_{\mathrm{ij}}=\mu+\alpha_{\mathrm{i}}+\varepsilon_{\mathrm{ij}}
$$

where $\mu=$ the overall mean; $\alpha=$ the effect of the plant extract treatment ( $\mathrm{i}=1-5$, for viability, apoptosis, and death; $\mathrm{i}=1-6$ for intracellular ROS; $\mathrm{i}=1-3$ for isoprostane) and $\varepsilon=$ the error. Data are shown as least squares means \pm standard error of the mean for cell viability, intracellular ROS, and isoprostanes production; the apoptosis and death data are displayed as fold change over medium control. Differences with $P<0.05$ were considered statistically significant.

\section{RESULTS AND DISCUSSION}

This study tested the hypothesis that different tannin-rich plant extracts can help mitigate the excessive ROS production in BAEC, thus reducing lipid peroxidation damage. Extracts from PMG, TA, and $\mathrm{CH}$ have been characterized for main components belonging to the group of hydrolysable tannins, rich in gallotannins, ellagitannins, and gallic acid (Madrigal-Carballo et al., 2009; Vázquez et al., 2009; Chambi et al., 2013). Extract from GM are reported to be rich in condensed tannins, especially cathechins and epicatechins (Sazwi et al., 2013).

Results of cell viability after $12 \mathrm{~h}$ of stimulation with natural extracts and natural extracts with LPS are presented in Figure 1A and B, respectively. In general, cell viability differed depending on the extract tested where no significant changes were reported after PMG and GM treatments with or without LPS. Treatment with $\mathrm{CH}$ and TA extracts, however, resulted in a significant decrease of BAEC viability compared with controls, suggesting some cytotoxic effects of these extracts. Consistent with the findings from the present study, previous research showed a significant decrease of cell viability after $24 \mathrm{~h}$ of exposure to $200 \mu \mathrm{g} / \mathrm{mL} \mathrm{CH}$ extract in human breast cancer cells (Lee et al., 2011). Furthermore, ellagic acid showed a strong antiproliferative activity and reduced cell viability on 4 different human cancer cells (Losso et al., 2004). Lu et al. (2010) found that gallic acid had the capacity to reduce the percentage of cell viability in mouse brain endothelial cells; moreover, gallic acid and gallotannins represent about $95 \%$ of the total phenolic compounds in TA (Chambi, et al., 2013). Chestnut extract subjected to simulated digestion was tested at different concentrations (50-1,200 $\mu \mathrm{g} / \mathrm{mL}$ ) on intestinal epithelial cells viability, exerting cytotoxic activity when used at concentrations above
$400 \mu \mathrm{g} / \mathrm{mL}$ (Reggi et al., 2020). Alternatively, it was reported that PMG peel extracts had stimulating effect on proliferation of both PBMC and Caco-2 cells following a dose-response curve $(5-100 \mu \mathrm{g} / \mathrm{mL}$; Okonogi et al., 2007). Collectively, the findings from this study support the contention that bovine endothelial cells can either tolerate or respond negatively to different tannin extracts; in particular, $\mathrm{CH}$ and $\mathrm{TA}$ were responsible for about a $30 \%$ reduction of cell viability compared with the control with and without LPS stimulation. Therefore, results from this in vitro model suggest that $\mathrm{CH}$ and TA extracts should be further tested for their effects on endothelial functionality before in vivo testing to highlight possible harmful effect on dairy cattle productivity and health.

The BAEC were evaluated to ascertain whether the observed reduction in viable cell number was ascribed, in part, to the induction of cell apoptosis. The amount of apoptosis and death in BAEC treated with plant extracts is presented in Figure 2. Specifically, mean changes in apoptosis with and without LPS are presented in Figure 2A and C, respectively; mean changes in death with and without LPS are presented in Figure $2 \mathrm{~B}$ and $\mathrm{D}$, respectively. The apoptosis assay was indicative of programmed cell death, whereas the death assay measured the cytotoxic effect of the tested extracts. The $\mathrm{CH}$ extract induced a significant increase $(P<$ 0.01) of both apoptosis and death compared with the negative control; furthermore, $\mathrm{CH}$ showed significantly $(P<0.05)$ more cell death compared with LPS control, whereas no effect was observed on cell apoptosis. The effect of $\mathrm{CH}$ extract on BAEC apoptosis was consistent with the viability results. The TA extract did not report any increase of apoptosis, which was in disagreement with the reduced cell viability registered with or without LPS stimulation; however, a slight, even if not significant, increase was reported for cell death compared with negative control, which might have influenced results on cell viability. The GM extract induced a significant $(P<0.01)$ increase of both apoptosis and death in the cultured cells after LPS exposure compared with the LPS control. The GM extract is characterized by condensed tannins (Desmarchelier et al., 1997). In particular, catechin content is around $76 \%$ and epicatechin content is $1.5 \%$ (Kassim et al., 2011), with the former being identified as the major bioactive compound in GM (Anggraini et al., 2011). Cathechins were reported to exert effect on cell growth and apoptosis in different carcinoma cell lines (Horie et al., 2005). Results on cell viability and apoptosis in the present study may suggest that GM extract induced cell apoptosis without effect on growth inhibition in cultured BAEC; moreover, results suggested that GM 
extract did not protect cell culture from LPS exposure compared with the other tested extracts. A dose of 100 $\mu \mathrm{g} / \mathrm{mL}$ of different antioxidant compounds extracted from PMG juice was able to induce apoptosis in human colon cancer cell lines after $24 \mathrm{~h}$ of exposure (Seeram et al., 2005). In the present research, however, PMG extract did not enhance BAEC apoptosis and death with or without LPS stimulation. As such, results on both cell apoptosis and death and viability highlighted that PMG natural extract did not have a negative effect on BAEC physiology in culture. Previous studies have demonstrated the positive effect of PMG extract as feed supplement in different physiological phases, such as in postpartum Holstein cows under heat stress conditions (Khorsandi et al., 2019) and during the transition period (Safari et al., 2018). In particular,
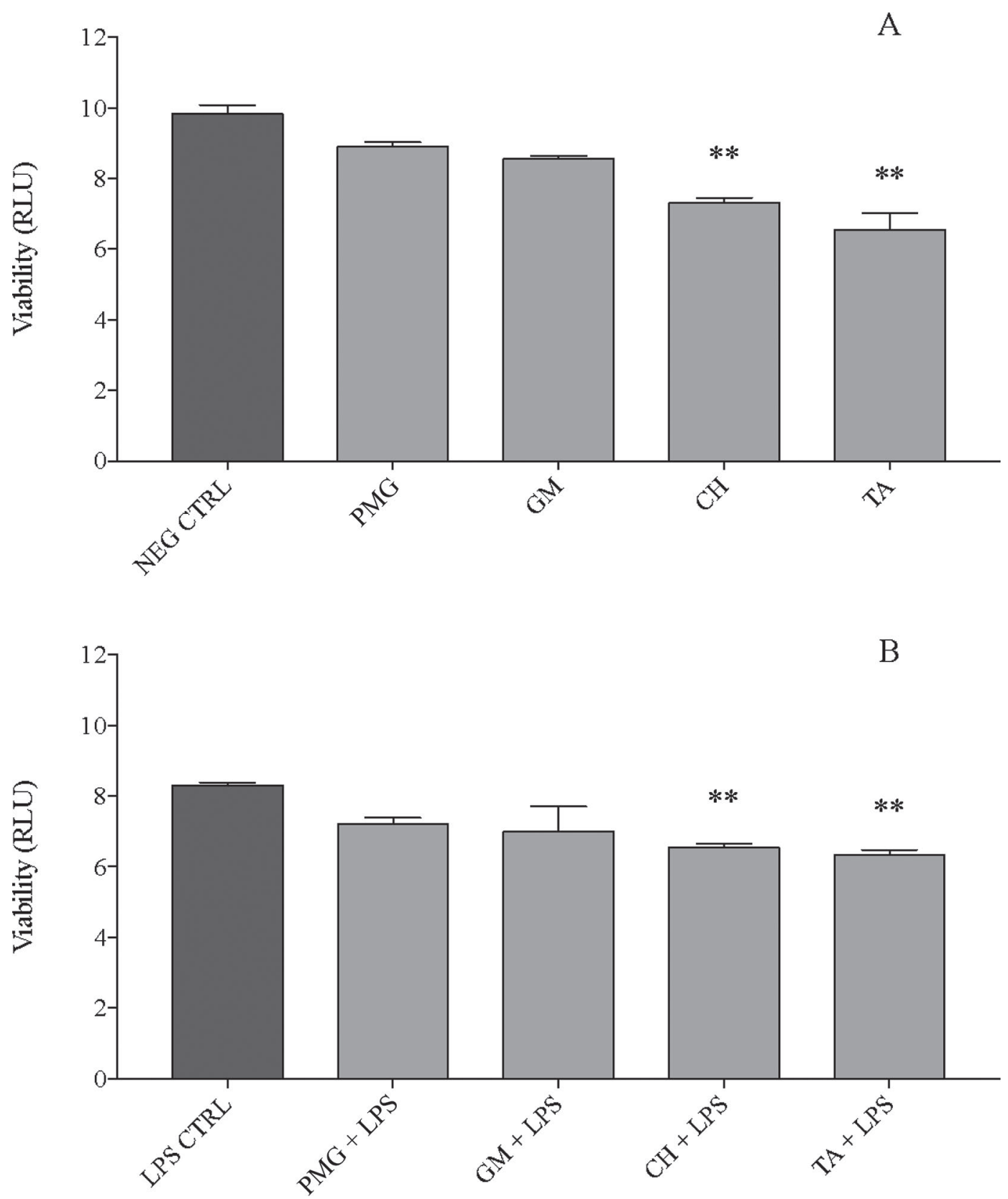

Figure 1. Mean changes in bovine aortic endothelial cell viability after $12 \mathrm{~h}$ of exposure to $80 \mu \mathrm{g} / \mathrm{mL}$ concentration of (A) natural extracts and (B) natural extracts with LPS, expressed as relative luminescence units (RLU). Dark gray bars represent the mean of controls; negative control (NEG CTRL) indicates untreated cells and LPS positive control (LPS CTRL) indicates cells after $12 \mathrm{~h}$ of LPS exposure. Light gray bars represent different treatments $(\mathrm{PMG}=$ pomegranate; $\mathrm{GM}=$ gambier; $\mathrm{CH}=$ chestnut; $\mathrm{TA}=$ tara). Error bars represent $\mathrm{SEM}$. $* * P<0.01$. 
PMG supplementation improved ruminal fermentation (Khorsandi et al., 2019) and increased milk yield and milk composition (Abarghuei et al., 2013) in dairy cattle. In a study by Oliveira et al. (2010), calves were fed with 5 or $10 \mathrm{~g} / \mathrm{d}$ of a dried PMG extract rich in polyphenols, resulting in a dose of 0.85 or $1.70 \mathrm{mg}$ of gallic acid equivalent/d. The dosages chosen for PMG were extrapolated from studies with human subjects in which clinical benefits to consuming polyphenols from PMG juice were reported (Pantuck et al., 2006; Heber et al., 2007). Furthermore, in a study by Natalello et al. (2020) lambs fed $200 \mathrm{~g}$ of PMG by-product/ $\mathrm{kg}$ of DM showed an improved fatty acid composition in muscle, with no negative effect on animal performances.

Results of the intracellular ROS production in BAEC after $12 \mathrm{~h}$ of stimulation with natural extracts and LPS are presented in Figure 3. Under physiological conditions, a limited amount of ROS is produced as a consequence of the cell metabolic activity, and this was reflected in our findings. As expected, LPS exposure can induce higher ROS production compared with un- treated control cultures (Contreras et al., 2012). After LPS stimulation, intracellular ROS production was significantly $(P<0.05$ for TA, $P<0.01$ for GM and $\mathrm{CH}$, and $P<0.001$ for PMG) lower in all of the tested extract treatments. The extent of the antioxidant activity of PMG, GM, CH, and TA was different according to the tested extract showing a reduction of $63,45,51$, and $27 \%$ compared with the LPS controls, respectively. Results on cell viability in BAEC treated with PMG and GM extracts suggested that the extent of ROS reduction in these treatments reflect the antioxidant ability of the plant extracts. Accordingly, PMG peel extracts evidenced an antioxidant effect on bovine mammary epithelial cells BME-UV1 inducing a reduction of $30 \%$ of ROS production after LPS exposure; such reduction was observed at a concentration of $10 \mu \mathrm{g} / \mathrm{mL}$ PMG peel extract, whereas no effect was observed for a lower extract concentration (Mastrogiovanni et al., 2018). Cathechins in GM extract may be responsible for its antioxidant activity; indeed, it has been reported that green tea cathechins can exert direct and indirect
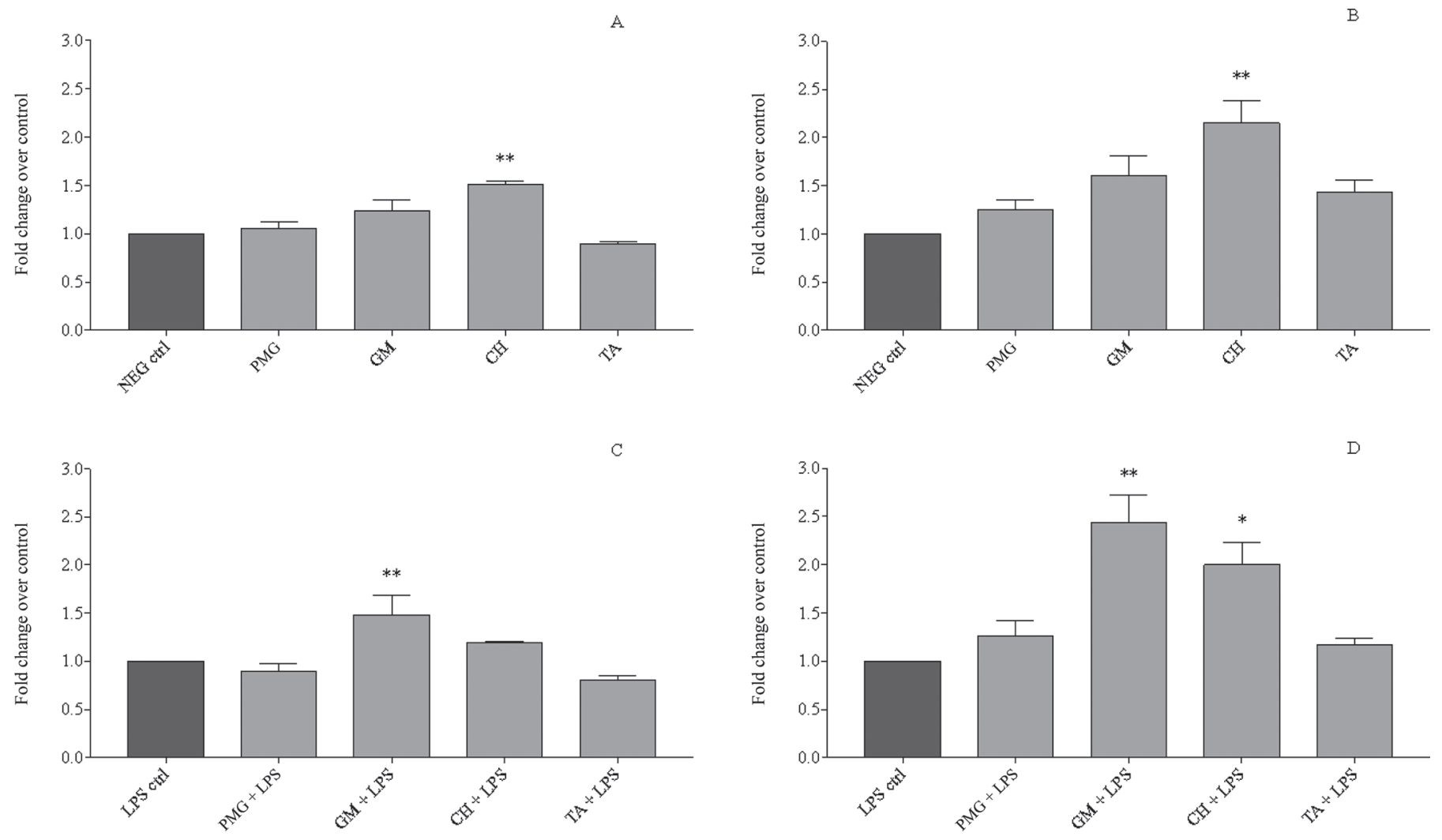

Figure 2. YO-PRO-1 and propidium iodide from a commercial kit (Thermo Fisher Scientific, Waltham, MA) of bovine aortic endothelial cell staining, displayed as fold change over medium control. Mean changes in (A) apoptosis and (B) death of cells after $12 \mathrm{~h}$ of exposure to $80 \mu \mathrm{g} /$ $\mathrm{mL}$ concentration of natural extracts, and mean changes in (C) apoptosis and (D) death of cells after $12 \mathrm{~h}$ of exposure to $80 \mu \mathrm{g} / \mathrm{mL}$ concentration of natural extracts and LPS. Dark gray bars represent the mean of negative (NEG ctrl; no treatment) and LPS positive control (LPS ctrl). Light gray bars represent different treatments $(\mathrm{PMG}=$ pomegranate; $\mathrm{GM}=$ gambier; $\mathrm{CH}=$ chestnut; TA $=$ tara $)$. Error bars represent SEM. $* P<0.05, * * P<0.01$. 
antioxidant effects on the cardiovascular system (Babu et al., 2008). On the contrary, the loss of cell viability in $\mathrm{CH}$ and TA treatments could have partly affected ROS production, suggesting an overestimation of the ability of the extracts to neutralize ROS. The results obtained on the antioxidant capacity of plant extracts tested in vitro should be confirmed in dairy cows, especially under oxidative stress conditions. Recent research on PMG by-products supplementation in transition dairy cows resulted in enhanced overall antioxidant capacity and limited the lipid peroxidation (Safari et al., 2018). Liu et al. (2013) reported an improvement of oxidative status in transition dairy cows fed the same $\mathrm{CH}$ extract used in the present study, at a level of 10 $\mathrm{g}$ of $\mathrm{CH}$ tannin $/ \mathrm{kg}$ of diet (DM basis). Furthermore, Valenti et al. (2019) reported a limited effect of tannin supplementation on lamb growth performances and meat oxidative stability; in this research lambs were fed a concentrate-based diet supplemented with $4 \%$ tannin extracts from mimosa, chestnut, or tara. To the best of our knowledge, no data are available on the quantity of tannins that can reach the blood flow after digestion and absorption; thus, it is difficult to relate an in vivo dosage fed to animals to an in vitro model concentration. However, in a study by Reggi et al. (2020), the effect of $\mathrm{CH}$ and quebracho tannin extracts on antimicrobial, antioxidant, and cytomodulatory activity in intestinal epithelial cells (IPEC-J2) was evaluated before and after in vitro digestion. In particular, the antioxidant activity of $\mathrm{CH}$ extract was halved after digestion compared with undigested extract.

In the light of the results shown, PMG extract turned out to be the best candidate for further studies to point out its efficacy as a dairy cow feed supplement during oxidative stress condition. The PMG extract was further investigated for IsoP formation; for this purpose, AAPH was used to mimic the excessive free radical ROS exposure as occurs in in vivo oxidative stress condition. The free radicals produced by AAPH treatment are able to attack cell phospholipids membrane, thus producing IsoP with harmful effect on dairy cattle (Mavangira and Sordillo, 2018). These compounds are indeed considered to be the best biomarkers of oxidative stress status and lipid peroxidation (Czerska et al., 2016). Isoprostanes are prostaglandin (PG)-like substances produced in vivo independently of cyclooxygenase enzymes, primarily by free radical-induced peroxidation of arachidonic acid (Montuschi et al., 2004) as well as other PUFA such as docosahexaenoic acid and eicosapentaenoic acid (Weinberger et al., 2015). Concentrations of IsoP produced by BAEC after exposure to PMG natural extract and AAPH are reported in Table 1. The following 6 molecules were identified, and all are derived from arachidonic acid: 5-iPF $2 \alpha, 8$-iso-15R-PGF $\mathrm{PG}_{2 \alpha}, 8$-iso- $\mathrm{PGF}_{2 \alpha}, 8$-12-iso-iPF $2 \alpha$, 8-iso- $\mathrm{PGA}_{1}$, and 8-iso- $\mathrm{PGA}_{2}$. As expected, the detected IsoP showed an increasing trend in cells stimulated with AAPH compared with untreated cells. In particu-

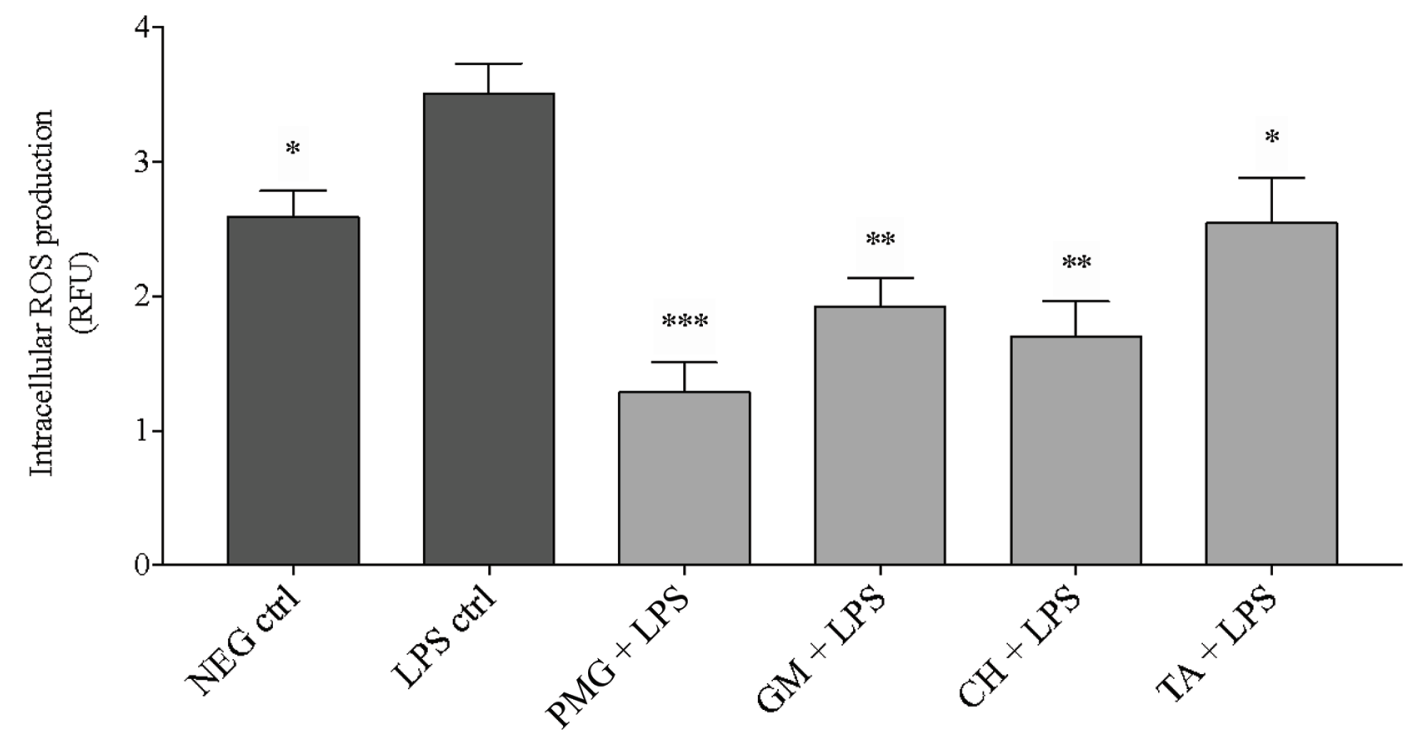

Figure 3. Mean changes in bovine aortic endothelial cell intracellular reactive oxygen species (ROS) production after $12 \mathrm{~h}$ of exposure to $80 \mu \mathrm{g} / \mathrm{mL}$ concentration of natural extracts with LPS, expressed as relative fluorescence unit (RFU). Dark gray bars represent the mean of controls; negative control (NEG ctrl) is untreated cell and LPS positive control (LPS ctrl) is cell after $12 \mathrm{~h}$ of LPS exposure. Light gray bars represent different treatments $(\mathrm{PMG}=$ pomegranate; $\mathrm{GM}=$ gambier; $\mathrm{CH}=$ chestnut; $\mathrm{TA}=$ tara $)$. Error bars represent $\mathrm{SEM}$. ${ }^{*} P \leq 0.05,{ }^{*} P$ $<0.01,{ }^{* * *} P<0.001$. 
Table 1. Concentrations of isoprostane (nM) in bovine aortic endothelial cells after $6 \mathrm{~h}$ of stimulation with 80 $\mu \mathrm{g} / \mathrm{mL}$ pomegranate and $5 \mathrm{~m} M \mathrm{AAPH}$

\begin{tabular}{lccccc}
\hline \multicolumn{3}{c}{ Treatment $^{2}$} \\
\cline { 2 - 4 } Isoprostane $^{1}$ & $\begin{array}{c}\text { Negative } \\
\text { control }\end{array}$ & $\begin{array}{c}\text { AAPH } \\
\text { control }\end{array}$ & $\begin{array}{c}\text { PMG } \\
+ \text { AAPH }\end{array}$ & SEM & $P$-value \\
\hline $5-$-PF $_{2 \alpha}$ & 0.10 & 0.23 & 0.20 & 0.03 & NS \\
8-iso-15R-PGF & 0.10 & 0.10 & 0.10 & 0.00 & NS \\
8-iso-PGF & 0.20 & 0.23 & 0.23 & 0.02 & NS \\
$8-12$-iso-iPF & 0.37 & 0.47 & 0.47 & 0.03 & NS \\
8-iso-PGA & $0.47^{\text {ab }}$ & $0.53^{\mathrm{b}}$ & $0.33^{\mathrm{a}}$ & 0.03 & $* *$ \\
8-iso-PGA & $0.47^{\mathrm{a}}$ & $1.43^{\mathrm{c}}$ & $0.73^{\mathrm{b}}$ & 0.08 & $*$ \\
\hline
\end{tabular}

${ }^{\mathrm{a}-\mathrm{c}}$ Mean values with different letters differ at $P<0.05$.

${ }^{1} 5$-iPF $\mathrm{PF}_{2 \alpha}=5,9 \alpha, 11 \alpha$-trihydroxy-(8$\left.\beta\right)$-prosta-6E,14Z-dien-1-oic acid; 8-iso-15R-PGF $\mathrm{P}_{2 \alpha}=8$-iso-15(R)-prostaglandin $\mathrm{F}_{2 \alpha} ; 8$-iso- $\mathrm{PGF}_{2 \alpha}=8$-iso-prostaglandin $\mathrm{F}_{2} ; 8$-12-iso-iPF $\mathrm{PF}_{2 \alpha}=12$-iso-5 $(\mathrm{R}), 6 \mathrm{E}, 14 \mathrm{Z}$-prostaglandin $\mathrm{F}_{2 \alpha} ; 8$-iso$\mathrm{PGA}_{1}=8$-iso-prostaglandin $\mathrm{A}_{1} ;$ 8-iso- $\mathrm{PGA}_{2}=8$-iso-prostaglandin $\mathrm{A}_{2}$.

${ }^{2}$ Treatments: negative control $=$ no treatment; $\mathrm{AAPH}=2,2$-azobis(2amidinopropane)-dihydrochloride; PMG $+\mathrm{AAPH}=$ pomegranate $+\mathrm{AAPH}$.

$* P<0.05 ; * * * P<0.001$

lar, IsoP 8-iso-PGA 1 and 8-iso-PGA 2 were influenced by $\mathrm{PMG}$ treatment, showing lower concentrations after AAPH exposure than AAPH control; however, the magnitude of the reduction was about 35 and $50 \%$ in IsoP 8-iso-PGA $\mathrm{PG}_{1}$ and 8-iso- $\mathrm{PGA}_{2}$, respectively. From the present results, IsoP 8-iso- $\mathrm{PGA}_{1}$ and 8-iso- $\mathrm{PGA}_{2}$ turned out to be the most abundant markers of oxidative stress in cultured BAEC. The observed reduction of IsoP in BAEC treated with PMG may be due to its ability to neutralize ROS generated from AAPH with a protective role against lipid peroxidation damage. This result was in accordance with the significant reduction measured in intracellular ROS detected in BAEC culture treated with PMG natural extract.

The IsoP 8-iso-PGA ${ }_{1}$ and 8-iso-PGA 2 represent dehydration products of 8-iso-prostaglandin $\mathrm{E}_{2}$. Recently, these IsoP were found in the plasma from cows during the transition into the early dry period to assess their role as biomarkers of potential damage on cow tissues (Putman et al., 2018). The authors speculated opposite roles for IsoP 8-iso-PGA $\mathrm{PA}_{1}$ and 8-iso- $\mathrm{PGA}_{2}$ with a pro-inflammatory and anti-inflammatory function, respectively (Putman et al., 2018). The present results suggest that PMG may be involved in the byosynthesis of IsoP during inflammation or under oxidative stress condition.

Overall, among the different plant natural extracts tested on cultured BAEC, PMG was the most tolerable without any adverse effect on cell viability and apoptosis. Moreover, PMG was able to reduce intracellular ROS production with a protective effect against membrane lipid peroxidation. Further studies should be implemented in dairy cows to determine the appropriate dose of PMG that can be consumed safely but has a positive effect on animal health. The possibility that
PMG could be used as a natural feed supplement to improve antioxidant defenses may represent a novel strategy to reduce oxidative stress and disease susceptibility in dairy cattle.

\section{ACKNOWLEDGMENTS}

The authors have not stated any conflicts of interest.

\section{REFERENCES}

Abarghuei, M. J., Y. Rouzbehan, A. Z. M. Salem, and M. J. Zamiri. 2013. Nutrient digestion, ruminal fermentation and performance of dairy cows fed pomegranate peel extract. Livest. Sci. 157:452-461. https://doi.org/10.1016/j.livsci.2013.09.007.

Anggraini, T., T. Akihiro, Y. Tomoyuki, and I. Tomio. 2011. Antioxidative activity and catechin content of four kinds of Uncaria gambir extracts from West Sumatra, Indonesia. Afr. J. Biochem. Res. 5:33-38.

Babu, P. V. A., and D. Liu. 2008. Green tea catechins and cardiovascular health: An update. Curr. Med. Chem. 15:1840-1850. https:/ /doi.org/10.2174/092986708785132979.

Castillo, C.. V. Pereira, Á. Abuelo, and J. Hernández. 2013. Effect of supplementation with antioxidants on the quality of bovine milk and meat production. Sci. World J. 2013:616098. https://doi.org/ http://dx.doi.org/10.1155/2013/616098.

Chambi, F., R. Chirinos, R. Pedreschi, I. Betalleluz-Pallardel, F. Debaste, and D. Campos. 2013. Antioxidant potential of hydrolyzed polyphenolic extracts from tara (Caesalpinia spinosa) pods. Ind. Crops Prod. 47:168-175. https://doi.org/10.1016/j.indcrop.2013 .03 .009 .

Contreras, G. A., S. A. Mattmiller, W. Raphael, J. C. Gandy, and L. M. Sordillo. 2012. Enhanced n-3 phospholipid content reduces inflammatory responses in bovine endothelial cells. J. Dairy Sci. 95:7137-7150. https://doi.org/10.3168/jds.2012-5729.

Czerska, M., M. Zieliński, and J. Gromadzińska. 2016. IsoprostanesA novel major group of oxidative stress markers. Int. J. Occup. Med. Environ. Health 29:179-190. https://doi.org/10.13075/ ijomeh.1896.00596.

Desmarchelier, C., E. Mongelli, J. Coussio, and G. Ciccia. 1997. Evaluation of the in vitro antioxidant activity in extracts of $\mathrm{Un}$ caria tomentosa (Willd.) DC. Phytother. Res. 11:254-256. https: 
//doi.org/10.1002/(SICI)1099-1573(199705)11:3<254::AIDPTR76>3.0.CO;2-5.

Heber, D., N. P. Seeram, H. Wyatt, S. M. Henning, Y. Zhang, L. G. Ogden, M. Dreher, and J. O. Hill. 2007. Safety and antioxidant activity of a pomegranate ellagitannin-enriched polyphenol dietary supplement in overweight individuals with increased waist size. J. Agric. Food Chem. 55:10050-10054.

Horie, N., N. Hirabayashi, Y. Takahashi, Y. Miyauchi, H. Taguchi, and K. Takeishi. 2005. Synergistic effect of green tea catechins on cell growth and apoptosis induction in gastric carcinoma cells. Biol. Pharm. Bull. 28:574-579. https://doi.org/10.1248/bpb.28.574.

Huang, Q., X. Liu, G. Zhao, T. Hu, and Y. Wang. 2018. Potential and challenges of tannins as an alternative to in-feed antibiotics for farm animal production. Anim. Nutr. 4:137-150. https://doi.org/ 10.1016/j.aninu.2017.09.004.

Kadl, A., and N. Leitinger. 2005. The role of endothelial cells in the resolution of acute inflammation. Antioxid. Redox Signal. 7:17441754. https://doi.org/10.1089/ars.2005.7.1744.

Kassim, M. J., M. H. Hussin, A. Achmad, N. Hazwani Dahon, T. Kim Suan, and H. Safley Hamdan. 2011. Determination of total phenol, condensed tannin and flavonoid contents and antioxidant activity of Uncaria gambir extracts. Indones. J. Pharm. 22:50-59.

Khan, N. S., A. Ahmad, and S. M. Hadi. 2000. Anti-oxidant, prooxidant properties of tannic acid and its binding to DNA. Chem. Biol. Interact. 125:177-189. https://doi.org/10.1016/S0009 $-2797(00) 00143-5$.

Khorsandi, S., A. Riasi, M. Khorvash, and F. Hashemzadeh. 2019. Nutrients digestibility, metabolic parameters and milk production in postpartum Holstein cows fed pomegranate (Punica granatum L.) by-products silage under heat stress condition. Anim. Feed Sci. Technol. 255:114213. https://doi.org/10.1016/j.anifeedsci.2019 .114213 .

Lee, H. S., E. J. Kim, and S. H. Kim. 2011. Chestnut extract induces apoptosis in AGS human gastric cancer cells. Nutr. Res. Pract. 5:185-191. https://doi.org/10.4162/nrp.2011.5.3.185.

Liu, H. W., D. W. Zhou, and K. Li. 2013. Effects of chestnut tannins on performance and antioxidative status of transition dairy cows. J. Dairy Sci. 96:5901-5907. https://doi.org/10.3168/jds.2013-6904.

Losso, J. N., R. R. Bansode, A. Trappey II, H. A. Bawadi, and R. Truax. 2004. In vitro anti-proliferative activities of ellagic acid. J. Nutr. Biochem. 15:672-678. https://doi.org/10.1016/j.jnutbio 2004.06.004.

Lu, Y., F. Jiang, H. Jiang, K. Wu, X. Zheng, Y. Cai, M. Katakowski, M. Chopp, and S.-S. T. To. 2010. Gallic acid suppresses cell viability, proliferation, invasion and angiogenesis in human glioma cells. Eur. J. Pharmacol. 641:102-107. https://doi.org/10.1016/j .ejphar.2010.05.043.

Lykkesfeldt, J., and O. Svendsen. 2007. Oxidants and antioxidants in disease: Oxidative stress in farm animals. Vet. J. 173:502-511.

Madrigal-Carballo, S., G. Rodriguez, C. G. Krueger, M. Dreher, and J. D. Reed. 2009. Pomegranate (Punica granatum) supplements: Authenticity, antioxidant and polyphenol composition. J. Funct. Foods 1:324-329. https://doi.org/10.1016/j.jff.2009.02.005.

Mastrogiovanni, F., R. Bernini, L. Basiricò, U. Bernabucci, M. Campo, A. Romani, L. Santi, and N. Lacetera. 2020. Antioxidant and anti-inflammatory effects of pomegranate peel extracts on bovine mammary epithelial cells BME-UV1. Nat. Prod. Res. 34:14651469. https://doi.org/10.1080/14786419.2018.1508149.

Mavangira, V., and L. M. Sordillo. 2018. Role of lipid mediators in the regulation of oxidative stress and inflammatory responses in dairy cattle. Res. Vet. Sci. 116:4-14. https://doi.org/10.1016/j.rvsc.2017 .08 .002 .

Montuschi, P., P. J. Barnes, and L. J. Roberts. 2004. Isoprostanes: markers and mediators of oxidative stress. FASEB J. 18:17911800. https://doi.org/10.1096/fj.04-2330rev.

Motterlini, R., R. Foresti, R. Bassi, and C. J. Green. 2000. Curcumin, an antioxidant and anti-inflammatory agent, induces heme oxygenase-1 and protects endothelial cells against oxidative stress. Free Radic. Biol. Med. 28:1303-1312. https://doi.org/10.1016/ S0891-5849(00)00294-X.
Natalello, A., G. Hervás, P. G. Toral, G. Luciano, B. Valenti, A. G. Mendoza, M. Pauselli, A. Priolo, and P. Frutos. 2020. Bioactive compounds from pomegranate by-products increase the in vitro ruminal accumulation of potentially health promoting fatty acids. Anim. Feed Sci. Technol. 259:114355. https://doi.org/10.1016/j .anifeedsci.2019.114355.

Okonogi, S., C. Duangrat, S. Anuchpreeda, S. Tachakittirungrod, and S. Chowwanapoonpohn. 2007. Comparison of antioxidant capacities and cytotoxicities of certain fruit peels. Food Chem. 103:839846.

Oliveira, R. A., C. D. Narciso, R. S. Bisinotto, M. C. Perdomo, M. A. Ballou, M. Dreher, and J. E. P. Santos. 2010. Effects of feeding polyphenols from pomegranate extract on health. Growth, nutrient digestion, and immunocompetence of calves. J. Dairy Sci. 93:4280-4291. https://doi.org/10.3168/jds.2010-3314.

Pantuck, A. J., J. T. Leppert, N. Zomorodian, A. William, J. Hong, R. J. Barnard, N. Seeram, H. Liker, H. Wang, R. Elashoff, D. Heber, M. Aviram, L. Ignarro, and A. Belldegrun. 2006. Phase II study of pomegranate juice for men with rising prostate-specific antigen following surgery or radiation for prostate cancer. Clin. Cancer Res. 12:4018-4026. https://doi.org/10.1158/1078-0432.

Putman, A. K., J. L. Brown, J. C. Gandy, L. Wisnieski, and L. M. Sordillo. 2018. Changes in biomarkers of nutrient metabolism, inflammation, and oxidative stress in dairy cows during the transition into the early dry period. J. Dairy Sci. 101:9350-9359. https: //doi.org/10.3168/jds.2018-14591.

Reggi, S., C. Giromini, M. Dell'Anno, A. Baldi, R. Rebucci, and L. Rossi. 2020. In vitro digestion of chestnut and quebracho tannin extracts: Antimicrobial effect, antioxidant capacity and cytomodulatory activity in swine intestinal IPEC-J2 Cells. Animals (Basel) 10:195. https://doi.org/10.3390/ani10020195.

Ryman, V. E., N. Packiriswamy, and L. M. Sordillo. 2015. Role of endothelial cells in bovine mammary gland health and disease. Anim. Health Res. Rev. 16:135-149. https://doi.org/10.1017/ S1466252315000158.

Safari, M., E. Ghasemi, M. Alikhani, and S. Ansari-Mahyari. 2018. Supplementation effects of pomegranate by-products on oxidative status, metabolic profile, and performance in transition dairy cows. J. Dairy Sci. 101:11297-11309.

Sazwi, N. N., T. Nalina, and Z. H. A. Rahim. 2013. Antioxidant and cytoprotective activities of Piper betle, Areca catechu, Uncaria gambir and betel quid with and without calcium hydroxide. BMC Complement. Altern. Med. 13:351. https://doi.org/10.1186/1472 $-6882-13-351$.

Seeram, N. P., L. S. Adams, S. M. Henning, Y. Niu, Y. Zhang, M. G. Nair, and D. Heber. 2005. In vitro antiproliferative, apoptotic and antioxidant activities of punicalagin, ellagic acid and a total pomegranate tannin extract are enhanced in combination with other polyphenols as found in pomegranate juice. J. Nutr. Biochem. 16:360-367. https://doi.org/10.1016/j.jnutbio.2005.01.006.

Skowyra, M., V. Falguera, G. Gallego, S. Peiró, and M. P. Almajano. 2014. Antioxidant properties of aqueous and ethanolic extracts of tara (Caesalpinia spinosa) pods in vitro and in model food emulsions. J. Sci. Food Agric. 94:911-918. https://doi.org/10.1002/jsfa .6335.

Song, J., J. Li, J. Qiao, S. Jain, B. M. Evers, and D. H. Chung. 2009 PKD prevents $\mathrm{H}_{2} \mathrm{O}_{2}$-induced apoptosis via NF- $\kappa \mathrm{B}$ and p38 MAPK in RIE-1 cells. Biochem. Biophys. Res. Commun. 378:610-614. https://doi.org/10.1016/j.bbrc.2008.11.106.

Sordillo, L. M. 2016. Nutritional strategies to optimize dairy cattle immunity. J. Dairy Sci. 99:4967-4982. https://doi.org/10.3168/jds .2015-10354.

Sordillo, L. M. 2018. Symposium review: Oxilipids and the regulation of bovine mammary inflammatory responses. J. Dairy Sci. 101:5629-5641. https://doi.org/10.3168/jds.2017-13855.

Sordillo, L. M., and S. L. Aitken. 2009. Impact of oxidative stress on the health and immune function of dairy cattle. Vet. Immunol. Immunopathol. 128:104-109. https://doi.org/10.1016/j.vetimm.2008 .10 .305 . 
Sordillo, L. M., and W. Raphael. 2013. Significance of metabolic stress, lipid mobilization, and inflammation on transition cow disorders. Vet. Clin. North Am. Food Anim. Pract. 29:267-278. https://doi .org/10.1016/j.cvfa.2013.03.002.

Sordillo, L. M., H. SooHoo, K. M. Aherne, C. C. Reddy, and J. S. Hogan. 1998. A method to reduce glutathione peroxidase levels in primary endothelial cell cultures. Methods Cell Sci. 19:243-253. https://doi.org/10.1023/A:1009759132250.

Valenti, B., A. Natalello, V. Vasta, L. Campidonico, V. Roscini, S. Mattioli, M. Pauselli, A. Priolo, M. Lanza, and G. Luciano. 2019. Effect of different dietary tannin extracts on lamb growth performances and meat oxidative stability: Comparison between mimosa, chestnut and tara. Animal 13:435-443. https://doi.org/10 $.1017 /$ S1751731118001556.

Vázquez, G., J. González-Alvarez, J. Santos, M. S. Freire, and G. Antorrena. 2009. Evaluation of potential applications for chestnut (Castanea sativa) shell and eucalyptus (Eucalyptus globulus) bark extracts. Ind. Crops Prod. 29:364-370. https://doi.org/10.1016/j .indcrop.2008.07.004.

Weiss, N., Y. Y. Zhang, S. Heydrick, C. Bierl, and J. Loscalzo. 2001. Overexpression of cellular glutathione peroxidase rescues homocyst(e)ine-induced endothelial dysfunction. Proc. Natl. Acad. Sci USA 98:12503-12508. https://doi.org/10.1073/pnas.231428998.

Weinberger, B., D. Hirsch, K. Yin, and B. W. Spur. 2015. Chapter 21Lipid mediators and lung function, Pages 403-421 in Comparative
Biology of the Normal Lung (Second Edition). R. A. Parent, ed. Academic Press, MA. https://doi.org/https://doi.org/10.1016/ B978-0-12-404577-4.00021-7.

Xu, Z.-R., L. Hu, L. Cheng, Y. Qian, and Y. Yang. 2010. Dihydrotestosterone protects human vascular endothelial cells from $\mathrm{H}_{2} \mathrm{O}_{2-}$ induced apoptosis through inhibition of caspase-3, caspase- 9 and p38 MAPK. Eur. J. Pharmacol. 643:254-259. https://doi.org/10 .1016/j.ejphar.2010.06.039.

Yang, C., M. A. K. Chowdhury, Y. Huo, and J. Gong. 2015. Phytogenic compounds as alternatives to in-feed antibiotics: Potentials and challenges in application. Pathogens 4:137-156. https://doi .org/10.3390/pathogens4010137.

\section{ORCIDS}

F. Ciampi ๑ https://orcid.org/0000-0002-2831-834X

L. M. Sordillo @ https://orcid.org/0000-0001-8873-3134

J. C. Gandy (으 https://orcid.org/0000-0003-0558-9611

M. Caroprese $\odot$ https://orcid.org/0000-0002-5292-3291

M. Albenzio (ㄴ) https://orcid.org/0000-0003-3201-1102

A. Santillo @ https://orcid.org/0000-0003-0444-8649 